International Conference on Renewable Energies and Power Quality (ICREPQ'17)
Malaga (Spain), $4^{\text {th }}$ to $6^{\text {th }}$ April, 2017
Renewable Energy and Pourer Qualily. Fournal (RE\&PQJ)
ISSN 2172-038 X, No.15 April 2017

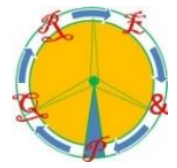

\title{
A Compact DC-DC Converter for Offshore Wind Farm Application
}

\author{
S. M. Alagab ${ }^{1}$, S.B. Tennakoon ${ }^{1}$ and C.A. Gould ${ }^{1}$ \\ ${ }^{1}$ School of Creative Arts and Engineering, Staffordshire University \\ College Road - Stoke on Trent, ST4 2DE (United Kingdom) \\ Phone number: +441782294861 \\ E-mail: samir.alagab@research.staffs.ac.uk, S.B.Tennakoon@staffs.ac.uk, C.A.Gould@staffs.ac.uk
}

\begin{abstract}
A DC-DC converter suitable for the grid integration of windfarms through a DC grid is presented. The operation is based on the Marx principle where charged capacitors are connected in series and parallel in turn to achieve the voltage transformation. The two inductors at the two ends of the converter are designed to resonate with the capacitors to create resonance forcing current zeros to enable zero current switching thereby reducing switching losses. The design of a $50 \mathrm{MW}, 6 \mathrm{kV} / 30 \mathrm{kV}$ DC-DC converter was carried out by analysis and simulation.
\end{abstract}

\section{Key words}

DC-DC converter, IGBT, offshore windfarm

\section{Introduction}

Due to the increasing distances of renewable and embedded generation in transmission and distribution systems, it is expected that the use of High Voltage Direct Current HVDC transmission and Medium Voltage Direct Current (MVDC) distribution systems for the grid integration of windfarms will grow worldwide [1]. One of the key components in such systems is the DC-DC converter, required to act as the interface between the generation, transmission and distribution voltage levels. Well established DC to DC converters based on pulse width modulated (PWM) converters which require high frequency switching are not suitable. Application to high voltage, high power systems mean series connection of devices and high power losses. Hence such converters are not technically and economically feasible. In order to combat these issues a new breed of DC-DC converters based on the age old concept of switching capacitors is being developed. Such converters are referred to as Switched Capacitor DC-DC Converters (SW-DC-DC) [2-6].

The structure of this paper is organized as follows: In Section 2 a number of DC-DC converter topologies are explained. From these Veilleux Converter is explained in section 3. An improved converter based on the Veilleux topology and the principle of operation are explained in Section 4 followed by the mathematical analysis in Section
5. In section 6 simulation results are presented and a comparison of both topologies is given in Section 7. Finally, the conclusion drawn in section 8 .

\section{DC-DC converter topologies}

A number of DC to DC converters suitable for high voltage applications are currently in research but none are not yet commercially available [5-8]. Non modular multilevel converters such as Flying Capacitor [9,10] and Diode Clamped [12] are not considered in this paper due to their complexity and difficulty of implementation. The modular, switched capacitor (SC) topologies explained in this paper are (a) Fibonacci, (b) Ladder (c) Interleaved (d) Doubler (e) Modular multilevel (MMC) and (f) Parallel-Series.

In all topologies the operation is based on charging and discharging of module capacitors in a particular sequence. In some cases, soft switching is used in order to reduce the switching losses enabling a higher frequency operation. If hard switching is used, switching frequencies above the power frequency becomes impractical due to unacceptably high losses. Topologies (a) to (d) are switched at high frequency and the literature does not indicate whether switching at low frequencies is feasible [2-4]. The Fibonacci topology has a high number of switches as depicted in Fig. 1(a) [2].

One module of the ladder converter as illustrated in Fig. 1(b), consists of two capacitors and four IGBTs switches leading to a complex structure and, the efficiency is low compared with the other topologies [3]. The interleaved topology requires the parallel connection of several two level converters at the input side as shown in fig. 1(c), and the multistage connection of capacitors at the output side with an interleaved switching scheme leads to a complex structure [4].

High switching frequency, low efficiency and the high number of components are also major issues. As shown in 
Fig. 1(d), the Doubler is similar to the Fibonacci topology and the same issues apply $[2,4]$.

MMC converter presented in $[5,12]$ is proposed for HVDC connected offshore wind farm. However, the number of IGBTs switches is high for HVDC application as illustrated in Fig. 1(e), which is expected. The seriesparallel DC-DC converter, is based on the Marx principle where, the capacitors are charged in parallel connected to the LV side voltage, and discharged in series to produce high voltage on the HV side as depicted in Fig. 1(f). This principle was used by Maneiro [9] to produce a DC to DC converter to tap power from a DC transmission line which can be used to power a remote area. Also the principle was used by Veilleux et al. to produce a DC-DC converter for off shore wind applications [7].

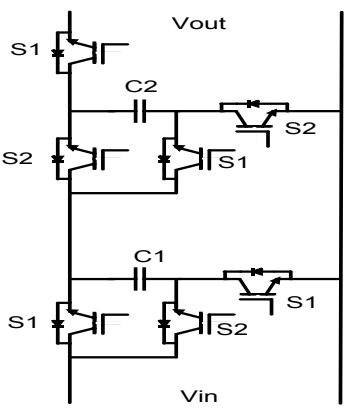

(a)

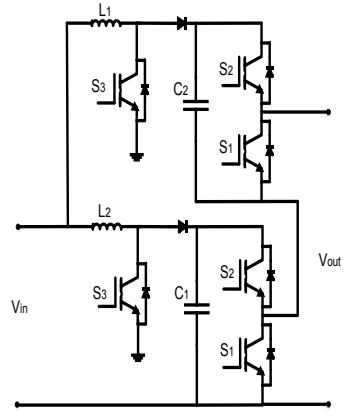

(c)

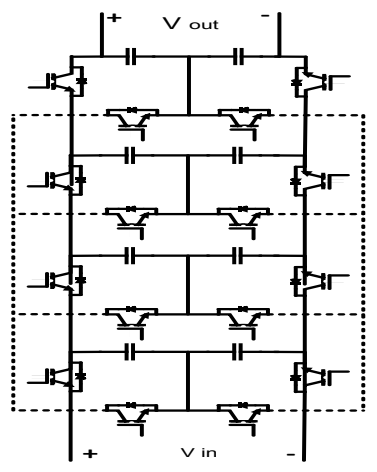

(e)

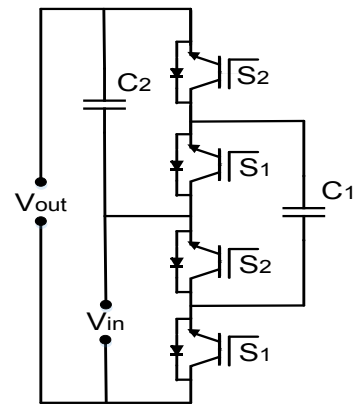

(b)

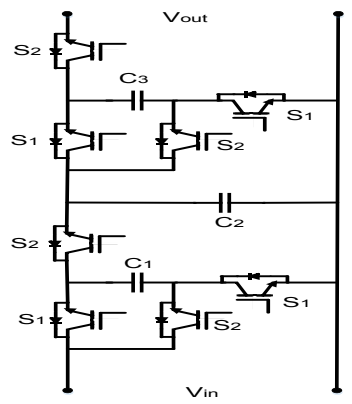

(d)

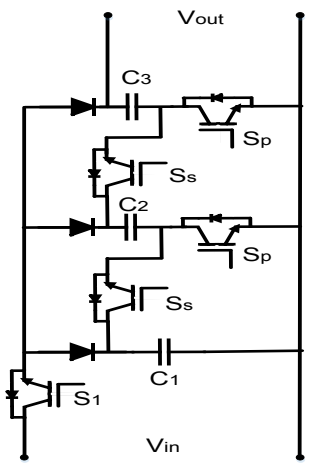

(f)
Fig. 1. Common switching DC-DC converter topologies: (a) Fibonacci, (b) The ladder, (c) interleaved boost, (d) Doubler, (e) multilevel modular MMC and (f) Parallel / Series Converter

\section{Veilleux Converter}

Fig. 1. Shows the Veilleux [7] converter with 5 submodule capacitors to achieve a voltage ratio of $1: 5$ and is based on the MARX principle. In addition, there are two capacitors at the two terminals to provide smoothing. The switching components are IGBTs and diodes. The operation can be divided into two sub periods. In the first sub period, the capacitors $C_{n}=(1,5)$ are charged in parallel from the LV source by switching the IGBTs $S_{\mathrm{pj}}(\mathrm{j}=1-4)$. The IGBTs $\mathrm{S}_{\mathrm{k}}(\mathrm{k}$ =1-4) are switched off and hence the charging currents flow through $S_{i n}, D_{i n}$, diodes $D_{n}(n=1-5)$ and the IGBTs $S_{p j}(j=1$ 4). In the second sub period, IGBTs $S_{\mathrm{sk}}$ are switched on and IGBTs $S_{P j}(j=1-4)$ are switched off to connect the capacitors in series to create a high voltage equal to 5 times the $\mathrm{LV}$ across the converter HV output.

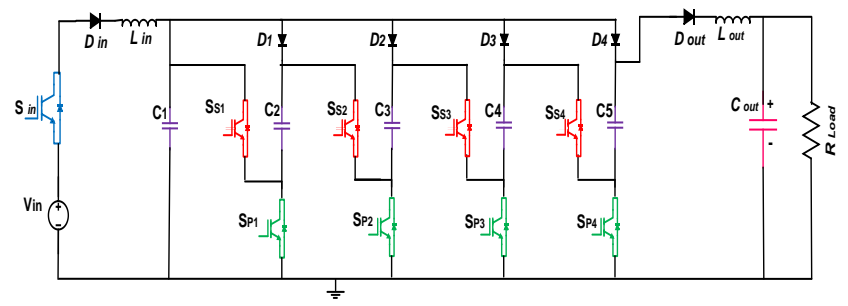

Fig. 2. Veilleux DC-DC Converter

A disadvantage of this topology is the number of IGBTs switches in the charging state $\mathrm{S}_{\mathrm{P}}$ is high and the increasing voltage stresses in the IGBTS in successive stages. The number of IGBTs can be reduced from 23 to 13 by combining function of 4 IGBTs $\left(\mathrm{S}_{\mathrm{Pl} 1}-\mathrm{S}_{\mathrm{P} 4}\right)$ to be performed by 4 diodes and 1 IGBT $\left(\mathrm{S}_{\text {valve }}\right)$ as shown in next section (proposed topology).

\section{Proposed topology}

\section{a. Circuit Configuration}

The structure of the converter as depicted in Fig. 2, can be broken down into three circuits; input circuit, middle circuit and the output circuit. The converter is aimed at application to a power collection system in an offshore windfarm grid connection system. A possible configuration showing the position of the DC to DC converter is shown in Figure 6. Where the specifications shown are used in the design.

Therefore the input circuit consists of an input DC voltage source of magnitude $\mathrm{V}_{\text {in }}=6 \mathrm{KV}$, input $\mathrm{HV}$ valve $\left(S_{\text {valve }}\right)$, and an input inductor $L_{\text {in }}$ connected in series with an input diode $\mathrm{D}_{\text {in }}$. Depending on the voltages in a particular application, and IGBT ratings a number of IGBTs in series are needed to form the High voltage valve ( $\left.S_{\text {valve }}\right)$.

The middle circuit comprises a number of IGBT switches, capacitors, and diodes $\mathrm{D}_{(1-8)}$. The number of capacitors denoted by " $\mathrm{n}$ " is set to 5 to create a voltage amplification of 5 . The capacitances in the 5 sub-modules are indicated by $\mathrm{C}_{\mathrm{n}}$, where $\mathrm{n}=(1,5)$. The switching 
components are IGBTs $S_{(1-4)}$, IGBT valve switches $S_{\text {valve, }}$, and diodes $\mathrm{D}_{(1-8)}$.

The output circuit consists of an output diode $\mathrm{D}_{\text {out }}$ connected in series with the output inductor $\mathrm{L}_{\text {out }}$, and one output capacitor $\mathrm{C}_{\text {out. }}$. The load, modelled by a pure resistor $\mathrm{R}_{\text {load, }}$, is connected in parallel.

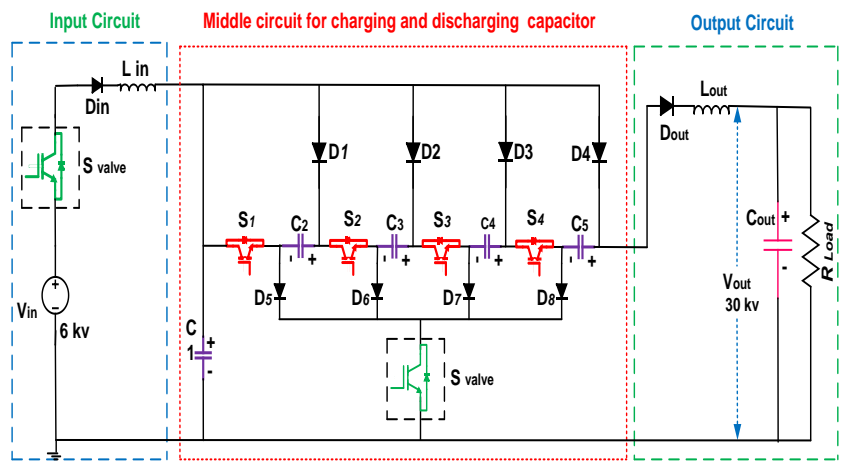

Fig. 3. Improved Veilleux DC-DC converter

\section{b. Operating Principle}

The operation of the converter can be divided into two equal sub-periods. During the first sub period all the cell capacitors $C_{n},(n=1,5)$ in the middle circuit are connected in parallel across the input low voltage (LV). The total charging current flows through the valve $\left(\mathrm{S}_{\text {valve }}\right)$, diode $\mathrm{D}_{\text {in }}$, input inductor $\mathrm{L}_{\mathrm{in}}$, and diodes $\mathrm{D}_{\mathrm{n}}$ where $\mathrm{n}=1,8$ and through the valve $S_{\text {valve }}$. Energy from the LV DC source transfers to the cell capacitors as illustrated in Fig. 4(a).

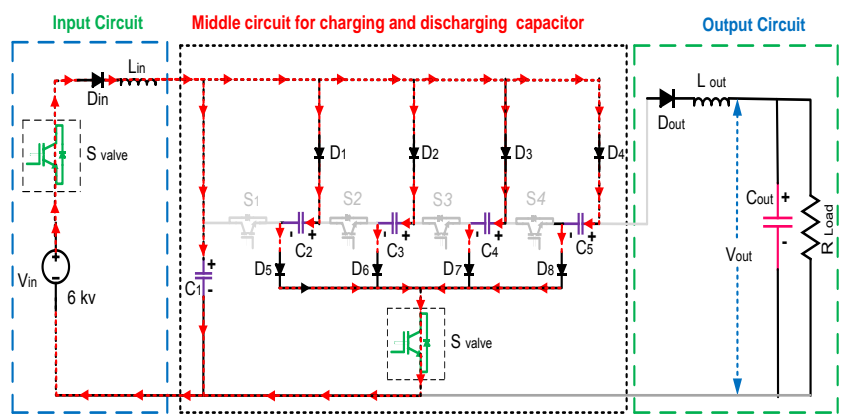

(a)

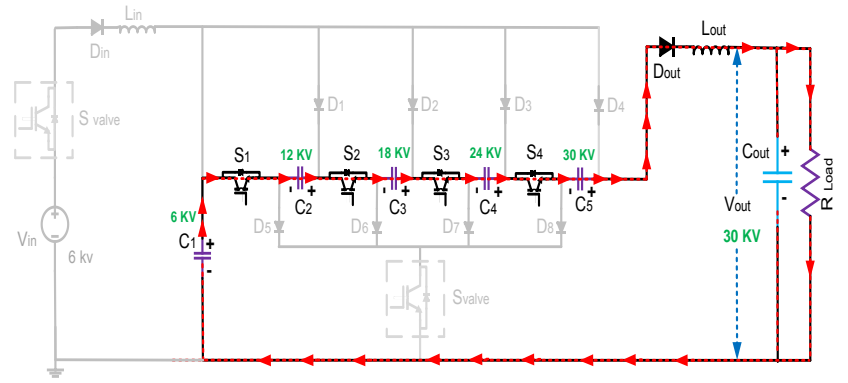

(b)

a) Connected the Capacitors in parallel during charging

b) Connected the Capacitors in Series during discharging

Fig. 4. Operation states of Improved Veilleux DC-DC converter
During the second sub-period of time, the cell capacitors are connected in series through IGBT switches $\mathrm{n}=1,4$ to produce the higher voltage as shown in Fig. 4(b). Energy transfers from the cell capacitors to the output capacitor $\mathrm{C}_{\text {out }}$. The inductor and capacitor combination must be designed so that the resonance frequency is less than switching frequency. This is used to implement soft switching to reduce the switching losses.

\section{Mathematical analysis}

The analysis of the improved Veilleux converter resulted in the following equations which can be used to determine the component values, optimise the switching frequency and determine the ratings of the IGBTs and diodes. The voltage transformation ratio is the same as the number of capacitors "n" and hence

$$
\mathrm{n}=\frac{\mathrm{v}_{\text {out }}}{\mathrm{V}_{\text {in }}}
$$

The output load ( $\left.\mathrm{R}_{\text {load }}\right)$ is dependent on the power rating of the converter and hence

$$
\mathrm{R}_{\text {load }}=\frac{\mathrm{V}_{\text {out }}^{2}}{\mathrm{P}}
$$

Where $\mathrm{P}$ is the power rating of the converter. The input inductance $\mathrm{L}_{\text {in }}$ is given by,

$$
\mathrm{L}_{\text {in }}=\frac{\mathrm{V}_{\text {out }}}{5} \cdot\left(\frac{\mathrm{I}_{\mathrm{Lin}}}{\Delta \mathrm{I}_{\mathrm{L}}}\right) \cdot \frac{\mathrm{T}_{\mathrm{S}}}{2}
$$

Where $\Delta \mathrm{I}_{\mathrm{L}}$ is the inductor current peak to peak ripple, $\mathrm{I}_{\mathrm{Lin}}$ is the input inductor current and $\mathrm{T}_{\mathrm{S}}$ is the switching time. The current of input inductor $\mathrm{L}_{\mathrm{in}}$ is a positive half sine wave during the first sub-period, charging the capacitors in $\mathrm{T}_{\mathrm{S}} / 2$ given as

$$
\mathrm{i}_{\text {Lin }}(\mathrm{t})=\mathrm{I}_{\text {Lin }}^{\mathrm{P}} \sin (\omega \mathrm{t})
$$

Where $\mathrm{I}_{\mathrm{Lin}}^{\mathrm{P}}$ is the peak inductor current. The capacitance value $\mathrm{C}_{\mathrm{n}}$ is given by

$$
\mathrm{C}_{\mathrm{n}}=\frac{\left(\mathrm{P} / \mathrm{nV} \mathrm{V}_{\mathrm{in}}\right) \cdot\left(1 / \mathrm{F}_{\mathrm{S}}\right)}{\Delta \mathrm{Vc}_{\mathrm{n}}}
$$

Where $\Delta V_{c}$ is the capacitor voltage ripple. The value of output inductance can be found as

$$
\mathrm{L}_{\text {out }}=\frac{\mathrm{V}_{\text {out }}\left(\mathrm{T}_{\mathrm{s}} / 2\right)}{\mathrm{F}_{\mathrm{S}} \cdot \Delta \mathrm{L}_{\text {out }}}
$$

The output capacitance value is given by,

$$
\mathrm{C}_{\text {out }}=\frac{\left(\mathrm{P} / \mathrm{nv} \text { in }_{\text {in }}\right) \cdot\left({ }^{T_{\mathrm{s}} / 2}\right)}{2 \pi \Delta \mathrm{v}_{\text {out }}}
$$

Where $\Delta \mathrm{V}_{\text {out }}$ is the peak to peak voltage ripple on the output capacitor voltage. A fixed frequency-switching pattern is applied to the circuit cells. Meanwhile, the equation (8) shows the resonant frequency $F_{\text {res }}$ for two stages.

$$
\mathrm{F}_{\text {res }}=\frac{1}{2 \pi \sqrt{\mathrm{LC}}}
$$




\section{Simulation studies}

The arrangement shown in Fig. 5, forms the basis for the simulation study. In this topology, the cluster is formed by two parallel lines of wind turbine, each containing 5 wind turbines in series. Hence, there is a total of 10 wind turbines; each rated at $5 \mathrm{MW}, 1.2 \mathrm{KV}$ [14]. Therefore, the total value of wind turbine cluster bus voltage is $6 \mathrm{KV}$ and $50 \mathrm{MW}$. Hence the DC-DC converter input voltage is $6 \mathrm{kV}$.

The DC - DC Converter is connected to the collection bus to step up the voltage to $30 \mathrm{kV}$ for MV Transmission using the equations derived in section 5 the parameters of the DC - DC converter were calculated which are given in Table.1.

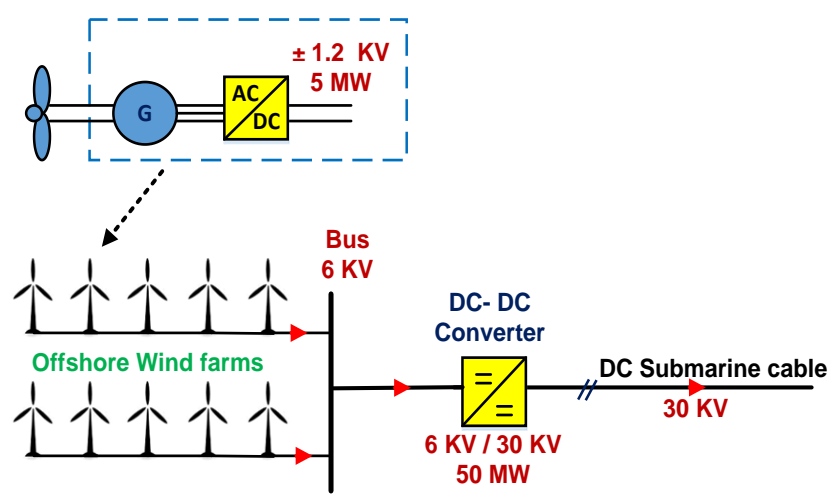

Fig. 5. DC collection topology system of wind farm

A switching frequency of $F_{S}=2 \mathrm{KHz}$ is used with fixed duty cycle of $d=0.5$. The load resistance was calculated using the $50 \mathrm{MW}$ power and the output voltage of $30 \mathrm{kV}$.

Table 1. System Parameters used for DCMC circuit simulation

\begin{tabular}{|l|c|c|}
\hline \multicolumn{1}{|c|}{ Parameter } & Symbol & value \\
\hline Input Voltage & $\mathrm{V}_{\text {in }}$ & $6 \mathrm{KV}$ \\
\hline Output Voltage & $\mathrm{V}_{\text {out }}$ & $30 \mathrm{kV}$ \\
\hline Load current & $\mathrm{I}_{\text {load }}$ & $1.667 \mathrm{KA}$ \\
\hline Rated power & $\mathrm{P}_{\text {rate }}$ & $50 \mathrm{MW}$ \\
\hline Switching frequency & $\mathrm{F}_{\mathrm{S}}$ & $2 \mathrm{KHz}$ \\
\hline Number of sub module capacitors & $\mathrm{C}_{\mathrm{n}}$ & 5 \\
\hline Sub module Capacitance & $\mathrm{C}_{\mathrm{l}_{1}}-\mathrm{C}_{5}$ & $694.5 \mu \mathrm{F}$ \\
\hline Output capacitance & $\mathrm{C}_{\text {out }}$ & $115 \mu \mathrm{F}$ \\
\hline Input inductance & $\mathrm{L}_{\text {in }}$ & $2.53 \mu \mathrm{H}$ \\
\hline Output inductance & $\mathrm{L}_{\text {out }}$ & $110 \mu \mathrm{H}$ \\
\hline Load resistance & $\mathrm{R}_{\text {load }}$ & $18 \Omega$ \\
\hline
\end{tabular}

The converter is simulated in Matlab/Simulink software package. The waveforms of input and output inductor currents, and the load voltage are depicted in Fig. 6(c) shows that the resonating inductor current increases to a peak around $26 \mathrm{KA}$ in $250 \mu \mathrm{s}$, which also flows through the IGBT. Inspection of the characteristics of the IGBT 5SNA 1200G450300 [15], shows that this is feasible. As the current begins to reverse in direction, the diode $\mathrm{D}_{\text {out }}$ blocks the current flow. The DC gain is 4.98 compared with the theoretical gain of 5. To the output voltage is $29.93 \mathrm{KV}$ which is very close to the design specification of $30 \mathrm{kV}$. The peak load current pf $1.662 \mathrm{kA}$ is very close to the design value of 1.667 .

(a)

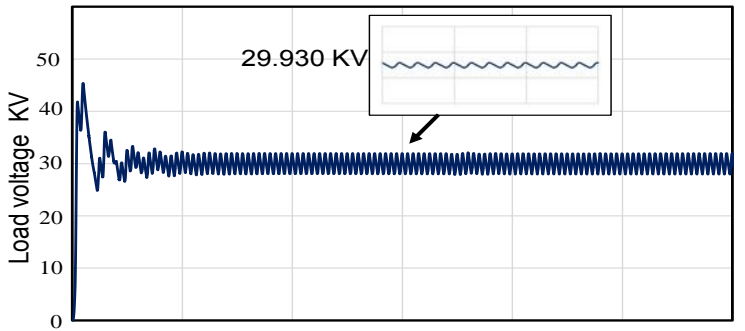

(b)

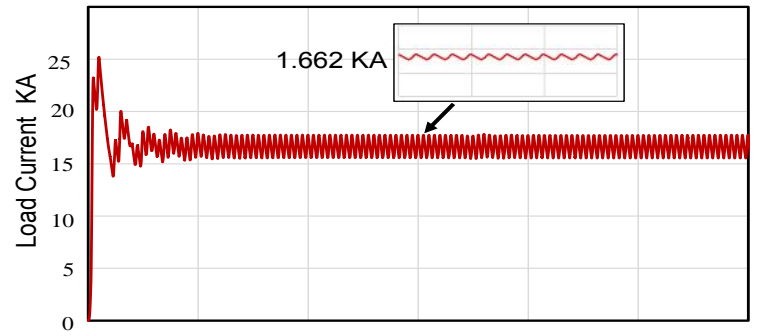

(c)

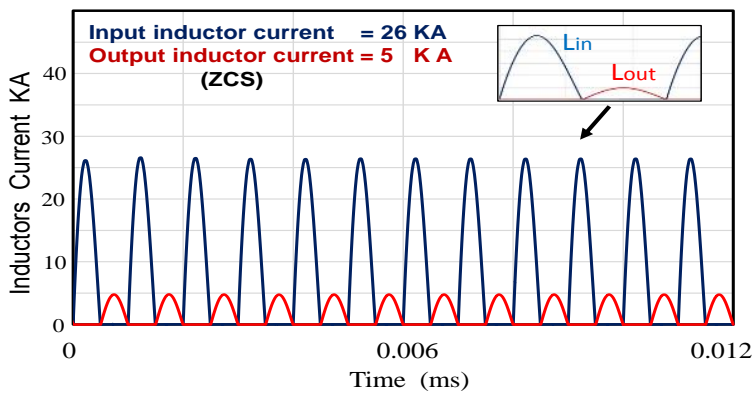

a) Output load voltage, b) Output load current and c) Inductor currents (ZCS)

Fig. 6. Simulation waveforms of the improved converter

\section{Comparison with the Veilleux converter}

A quantitative comparison was carried out using data from the output results by Matlab/ Simulink simulation, and the proposed configuration is evaluated and compared with Veilleux converters in terms of the power device count to highlight its advantages for high-voltage applications.

Both topologies, are operating with the same DC-DC Marx converter principle; hence, the comparison is made for the same three gains, same input voltage, same power rating, same load, same soft witching technique, and same switching frequency.

The output voltage and current of both topologies should be $30 \mathrm{KV} / 1667 \mathrm{~A}$ as designed. However, the output voltage of Veilleux topology is $29.59 \mathrm{KV}$, and the proposed topology is $29.93 \mathrm{KV}$. In addition, the load current of Veilleux topology is $1644 \mathrm{~A}$, and a proposed topology is 1662 A. numbers of IGBTs switches in gain (1:5) are 11 only in a proposed topology, but in a Veilleux topology are 20 as depicted in Fig. 8. 


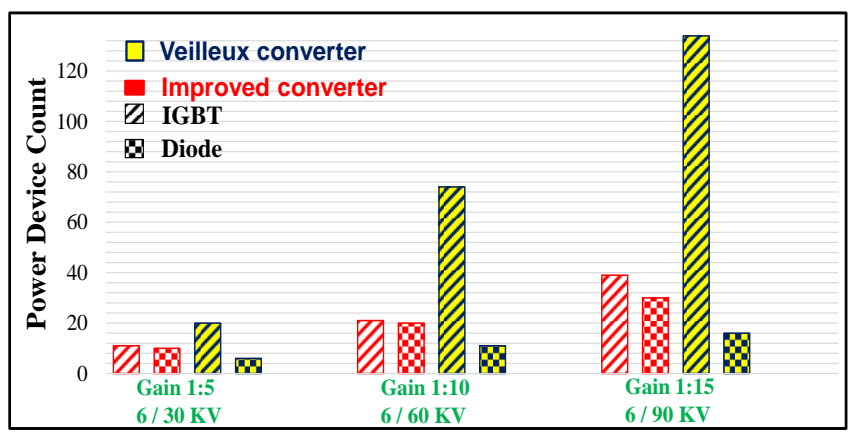

Fig. 7. Power device count comparison

\section{Conclusion}

The improved converter achieves the required gain of 5 with reduced components. Soft switching can be implemented and a method for calculating the resonant component values and the switching frequency is given. Also a design methodology for the determination of the circuit components and solid state devices is given.

\section{References}

[1] S. M. Alagab and C. Gould, "Review of wind farm power collection schemes," In Power Engineering Conference (UPEC), 50th International Universities 2015.

[2] J. C. Mayo-maldonado, S. Member, J. C. Rosas-caro, and P. Rapisarda, "Modeling Approaches for DC - DC Converters With Switched Capacitors," vol. 62, no. 2, pp. 953-959, 2015.

[3] H. Taghizadeh, A. M. Cross, R. Whitehouse, and C. Barker, "Switched Capacitor DC-DC Converters for HVDC Applications," pp. 1-9.

[4] A. Ponniran, K. Orikawa, and J. Itoh, "Interleaved High Boost Ratio Marx Topology DC-DC Converter."

[5] M. D. Seeman and S. R. Sanders, "Analysis and Optimization of Switched-Capacitor \{DC \}amp;\#x2013;DC Converters," 2006 IEEE Work. Comput. Power Electron., vol. 23, no. 2, pp. 216-224, 2006.

[6] X. Zhang and T. C. Green, "The Modular Multilevel Converter for High Step-Up Ratio DC-DC Conversion," Ind. Electron. IEEE Trans., vol. 62, no. 8, pp. 4925-4936, 2015.

[7] P. W. Lehn, B.-T. Ooi, and E. Veilleux, "Marx dc-dc converter for high-power application," IET Power Electron., vol. 6, no. April, pp. 1733-1741, 2013.

[8] A. Parastar, "High-Power Multilevel Step-Up DC / DC Converter for Offshore Wind Energy Systems," vol. 0046, no. c, pp. 4781-4788, 2015.

[9] S. Tennakoon, "Scalable Shunt Connected HVDC Tap Using the DC Transformer Concept," pp. 6-8.

[10] C. Cheng and L. He, "Flying-Capacitor-Clamped FiveLevel Inverter Based on Switched-Capacitor Topology," vol. 0046, no. c, 2016.

[11] A. Parastar, A. Gandomkar, and J. Seok, "HighEfficiency Multilevel Flying-Capacitor Renewable Energy Systems," vol. 62, no. 12, pp. 7620-7630, 2015.

[12] J. Zhao, Y. Han, X. He, C. Tan, J. Cheng, and R. Zhao, "Multilevel circuit topologies based on the switchedcapacitor converter and diode-clamped converter," IEEE Trans. Power Electron., vol. 26, no. 8, pp. 2127-2136,
2011.

[13] H. D. Offshore, "Multilevel Modular DC / DC Power Converter for Wind Energy Applications," vol. 62, no. 5, pp. 2879-2890, 2015.

[14] P. Lakshmanan, J. Liang, and N. Jenkins, "Assessment of collection systems for HVDC connected offshore wind farms," Electr. Power Syst. Res., vol. 129, pp. 75-82, Dec. 2015.

[15] ABB, "Surge currents for IGBT diodes," 2014.

\section{Biography}

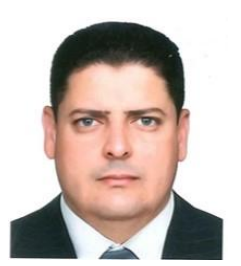

Samir Milad Alagab (Ph.D Researcher) was born in Tripoli Libya. He obtained his HND (Eng) Degree and MSc degree in Electrical Eng. from higher institute for preparing trainers- Zliten- Libya in 1996 and Staffordshire University, United Kingdom, in 2009, respectively. He worked as Electrical Engineer in Power Operation Department, High Line Division, Sirte Oil Company for Production, Manufacturing of Oil \& Gas, Libya and he worked as a lecturer assistant in the Department of Electrical Engineering at high professional institute for comprehensive professions, Khoms- Libya. Presently, he is working on his Ph.D, degree at Staffordshire University, Stoke-on-Trent, U.K. His research interest include renewable energy technologies, DC/DC converter for power collection in offshore wind farm.

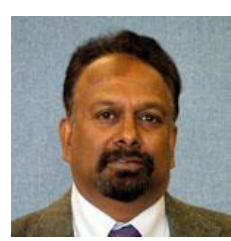

Sarath Tennakoon (M'87) received the B.Sc. degree in electrical engineering from the University of Moratuwa, Sri Lanka, the M.Sc. degree from the University of Aston, Birmingham, U.K., and the Ph.D. degree in Electrical Engineering and Electronics from the University of Central Lancashire, Lancashire, U.K. Currently, he is a Professor of power electronic systems and the Director of Centre for Energy Efficient Systems, Staffordshire University, Stoke-on-Trent, U.K. His research interests are DC grids and HVDC, power system protection, and power electronics and harmonics.

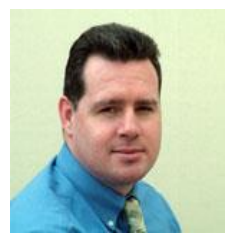

Dr. Chris Gould received the BEng (Hons) Degree in Engineering from Coventry University in 1996, Masters in Business Administration (MBA) from the University of Hertfordshire in 2006, and a $\mathrm{PhD}$ in Electrical and Electronic Engineering in the field of thermoelectricity from Staffordshire University in 2014. Chris is currently the Senior Lecturer in Electrical and Electronic Engineering, and the Award Leader for the BEng/MEng Electrical Engineering Award at Staffordshire University in the United Kingdom. Research interests include thermoelectricity, energy harvesting, energy storage, and semiconductor device modelling and simulation. 